\title{
SYLLOGISTIC EXPANSION IN THE LEIBNIZIAN REDUCTION SCHEME
}

\author{
Arman BESLER ${ }^{*}$
}

\begin{abstract}
The standard inferential scheme of traditional assertoric syllogistic, based on the initial chapters of Aristotle's Prior Analytics, employs single-premissed deductions, i.e., principles of immediate inference, in the reduction of imperfect valid moods to perfect moods. G. W. Leibniz (among others) has attempted to replace this scheme with his own version of syllogistic reduction (the core of which is, again, based on Aristotle's observations on syllogistic transformation), in which the principles of immediate inference themselves are modelled as (and hence justified by means of) valid syllogisms. This paper examines the place of this modelling, i.e. syllogistic expansion, of immediate inferences in Leibniz's scheme of syllogistic reduction (which he describes in his Nouveaux Essais and presents in one of his papers on syllogistic), and shows through this examination that the tenability of the whole scheme actually hinges on the interpretation to be given for the categorical propositional forms.
\end{abstract}

Keywords: Syllogistic Mood, Syllogistic Figure, Reduction, Immediate Inference, Leibniz

\section{LEIBNIZ'İN İNDİRGEME PLANINDA TASIMSAL GENLEŞTİRME}

Öz: Geleneksel asertorik tasım kuramının, Aristoteles'in Birinci Çözümlemeler'inin ilk bölümlerine dayanan standart çıkarım planı, eksik geçerli kipleri tam/mükemmel kiplere indirgemek için bazı tek öncüllü dedüktif çıkarımları, yani dolaysız çıkarım ilkelerini kullanır. G. W. Leibniz, bu planın yerine, özü itibariyle yine Aristoteles'in tasımsal dönüştürme hakkındaki gözlemlerine dayanan, kendi tasımsal indirgeme örneğini koymaya girişenlerden birisidir. Leibniz'in indirgeme planında, dolaysız çıkarım ilkelerinin kendileri, geçerli tasımlar olarak modellenir (ve dolayısıyla onlar yoluyla gerekçelendirilir). Bu çalışma, dolaysız çıkarımların bu modellemesinin, yani tasımsal genleştirmenin, Leibniz'in (Nouveaux Essais'de betimlediği ve tasım hakkındaki yazılarından birinde sunduğu) tasımsal indirgeme planındaki yerini incelemekte ve bu inceleme yoluyla bütün bir indirgeme planının savunulabilirliğinin, aslında, kategorik önerme biçimleri için verilecek yoruma bağlı olduğunu göstermektedir.

Anahtar Kelimeler: Tasım Kipi, Tasım Şekli, İndirgeme, Dolaysız Çıkarım, Leibniz

\footnotetext{
* Dr. Öğr. Üyesi I Asst. Prof.

Nevşehir Hacı Bektaş Veli Üniversitesi, Fen-Edebiyat Fakültesi, Felsefe Bölümü, Türkiye I Nevşehir Hacı Bektaş Veli University, Faculty of Sciences and Letters, Department of Philosophy, Turkey armanbesler@gmail.com Orcid Id: 0000-0002-0553-9131
}

Besler, A. (2018). Syllogistic Expansion in the Leibnizian Reduction Scheme. Kilikya Felsefe Dergisi, (2), 1-16. 


\section{Introduction: Superiority of the Indirect Method ${ }^{1}$}

The standard inferential scheme of traditional assertoric syllogistic, based on chs. 2-7 of Aristotle's Prior Analytics (PrA), ${ }^{2}$ employs two main methods of proof $^{3}$ and several single-premissed deductions from categorical propositions, traditionally called immediate inferences, ${ }^{4}$ for the perfection of imperfect valid moods. The direct method consists of deducing the conclusion of a given imperfect mood from its premisses, by means of eductive ${ }^{5}$ and oppositive ${ }^{6}$ inferences and a suitable perfect mood. The indirect method - alternatively proof by regress or per impossibile - consists of demonstrating the validity of a given imperfect mood by showing that once one affirms one of its premisses and denies its conclusion one cannot but deny its other premiss, again using a suitable perfect mood. The only immediate inference used in the indirect method is the law of contradiction from the traditional square of opposition: from the truth/falsity of an a/e/i/o categorical follows, respectively, the falsity/truth of an o/i/e/a categorical.

The indirect method is employed in the initial chapters of $\operatorname{PrA}$ and in the standard reduction scheme specifically for those imperfect moods which cannot be reduced (perfected) directly: i.e. Baroco(II) and Bocardo(III). The joint reason for these exceptions is that the eductive inferences employed in the direct method (i.e. simple and partial conversions) do not apply to $o$ categoricals, and the only conversion inference from an $a$ categorical yields an $i$ proposition, leaving in each of the two moods two particular premisses, from which no conclusion could follow. ${ }^{7}$

So, the direct method does not apply to some moods; however, the indirect method could alternatively be employed for reducing all the imperfect moods of the second and third figures - the only non-first figures both for Aristotle and the medieval tradition. ${ }^{8}$ Moreover, the employment of the indirect method does not have to take the shape of a reduction from an imperfect mood to a perfect mood: from any given valid mood of one

\footnotetext{
${ }^{1}$ I use throughout the text italicized lowercase letters " $a$ ", " $e$ ", " $i$ ", " $o$ " to indicate the four basic types of categorical proposition, capital letters " $\mathrm{A}$ ", " $\mathrm{B}$ ", " $\mathrm{C}$ " as term variables, and a non-Aristotelian idiom/order of predication. So the symbol, for instance, "A $i \mathrm{~B}$ " is to be read as "Some A is B" and "CeA" as "No C is $A$ ". 2 25a1-29b25; Aristotle (2009) pp. 2-12.

${ }^{3}$ A third, optional method employed (irrelevant to my discussion) is ecthesis (exposition). See Patzig (1968) p. 159 seqq. and Parsons (2014) pp. 23-24, for two different accounts of this disputable method.

$4 a$ - $o$ and $e$-i contradictions, and $a$-e contrareity in De Interpretatione, ch. 7, 17b16-25 (Aristotle, 1963, p. 48); $i$ o subcontrareity in De Int., ch. 10, 19b32-35 (ibid., p. 55). a-i and e-o subalternations in Book 2 of Topics, Section 1: 109a3-6. See Patzig (1968) p. 143, endnote 22. Some obverted forms appear in one of the charts that employ infinitized terms in De Int., ch. 10, 19 b30 (Aristotle, 1963, p. 55).

${ }^{5}$ I.e., vertere inferences such as conversion, obversion and contraposition. See Miller (1938) p. 19, for the label "eduction".

6 Two categorical propositions are opposed if and only if they have the same subject term and the same predicate term, although they may differ in propositional quality/quantity.

${ }^{7}$ By the traditional rule that reads: nil sequitur geminis ex particularibus unquam (Chenique, 2006, p. 209).

8 Parsons (2014) pp. 15-16. The medieval custom was to follow PrA, ch. 7, in considering (what are to be later identified as) the fourth-figure moods as indirect moods of the first figure.
} 
of the first three figures (whether perfect or imperfect) can be produced exactly two other valid moods, one of which is of one, and the other of the other, of the two remaining figures. This fact brings forth the idea of arranging a neater scheme of syllogistic reduction, especially in the context of a denial of the presence of a distinct fourth figure to which the indirect method does not in any way apply.

Such use of the indirect method as a method of syllogistic transformation, called conversio syllogismi (conversion/transformation of a syllogism), has been observed and illustrated by Aristotle in the second book of PrA. ${ }^{9}$ Aristotle nevertheless has not made out of conversio syllogismi a full-fledged alternative reduction scheme, most probably for the reason that the production of Darapti(III) and Felapton(III), which are among the fourteen Aristotelian valid moods, by means of conversio syllogismi necessitates the use of subaltern moods of the first and second figures, which he did not admit into his system. ${ }^{10}$

G. W. Leibniz, however, brought this idea to its end and proposed a full-fledged alternative reduction scheme for assertoric syllogistic. Leibniz considered his reduction scheme to constitute an inferentially more parsimonious alternative despite the fact that his syllogistic harbors both the fourth figure - and thus the eductive inferences - and the subaltern moods. The key to parsimony is the operation that I dub syllogistic expansion, i.e. expanding immediate inferences to valid (two-termed) syllogisms. In the following, an examination of the Leibnizian scheme and of the contribution of syllogistic expansion to it is available. The examination tries to show that the intended inferential parsimony had better be assessed from the standpoint of the interpretation of the categorical propositional forms.

\section{The Leibnizian Reduction Scheme}

Leibniz's reduction scheme yields a rather symmetrical assertoric syllogistic with 24 valid moods (including the subalterns), each of the four figures housing exactly six. Leibniz gives (i) a description of this scheme in his Nouveaux Essais sur l'Entendement Humain, Book IV, ch. $2, \S 1$, and ch. 17, §4, but (ii) the complete analysis is found in one of his logical papers from his mature period with the title "De Formis Syllogismorum Mathematice Definiendis" ${ }^{11}$ Hereon I give, depending on both sources, a simple account of the scheme with my own order of explanation.

\footnotetext{
${ }^{9}$ Chs. 8-10. See Patzig (1968) p. 154 (also for the label).

10 Ibid., p. 153.

${ }^{11}$ For (i), see Leibniz (1996) pp. 361-367 (Remnant and Bennett's English translation) and pp. 479-481 (original pagination); for (ii), see Leibniz (1966) pp. 105-111. Leibniz, contrary to his description in the Nouveaux Essais, holds in De Formis Syllogismorum that the fourth figure houses nine valid moods (so 27 in sum), but his account of the reduction of the fourth figure in that paper is absent. He might be adding to the fourth figure all of the so-called Theophrastian moods. In any case, my reconsctruction of the Leibnizian reduction of the fourth-figure will follow the symmetry mentioned in the Nouveaux Essais.
} 


\subsection{The logic of conversio syllogismi}

Conversio syllogismi, as stated above, is nothing other than the order-free application of the indirect method, so it can take the shape of reducing an imperfect mood by deducing (or producing) it from a suitable perfect mood. Since the common informal description of the indirect method lacks a logical justification of the method, it had better be replaced by a formal one. Actually the indirect method is implicitly based on the idea of propositional contraposition, so it can be reconstructed simply by using a portion of propositional logic. Now any given assertoric syllogistic mood can be reformulated in the following (material) conditional form:

\section{(C) $\mathrm{p} \rightarrow(\mathrm{q} \rightarrow \mathrm{r})$}

where " $\mathrm{p}$ " and " $\mathrm{q}$ " stand for the major and minor premisses respectively, and " $\mathrm{r}$ " for the conclusion of the mood, so that the mood is a valid inference if and only if its (C)-form is a valid formula. ${ }^{12}$ The method of indirect proof is then basically to show that the (C)-form of the given imperfect mood is a valid formula, by contraposing the main consequent (i.e. " $\mathrm{q} \rightarrow \mathrm{r}$ " to obtain " $\sim \mathrm{r} \rightarrow \sim \mathrm{q}$ "), and if need be, by few applications of the equivalence (let which be named here interchange of premisses)

(IP) $\phi \rightarrow(\psi \rightarrow \chi) \equiv \psi \rightarrow(\phi \rightarrow \chi)$

to the resulting forms, to obtain an equivalent (C)-form of a perfect mood (which is a valid formula by definition). ${ }^{13}$ So consider first Baroco(II):

$\mathrm{B} a \mathrm{C}$.

$\mathrm{AoC}$.

Therefore, AoB.

This mood takes the (C)-form

$$
\mathrm{B} a \mathrm{C} \rightarrow(\mathrm{AoC} \rightarrow \mathrm{AoB})
$$

which is equivalent to

$$
\mathrm{B} a \mathrm{C} \rightarrow(\mathrm{A} a \mathrm{~B} \rightarrow \mathrm{A} a \mathrm{C})
$$

\footnotetext{
12 Since the conditional is only material, the apodeictic character of the conclusion of the syllogistic inference is to be restored by the validity of the conditional.

${ }^{13}$ Patzig uses a substitution instance of 3.37 of Russell and Whitehead's Principia Mathematica to explain the indirect method and accordingly conversio syllogismi; see his (1968) p. 151 seqq. I preferred the above version, for it more clearly exhibits the centrality of propositional contraposition - or the related Stoic indemonstrable, modus (tollendo) tollens - to the idea of indirect proof. Aristotle's is surely not a logic of propositions, but he implicitly uses some propositional rules, among which is that of contraposition: ibid., p. 151, endnote 36. (Patzig calls it "transposition".)
} 
by contraposition (and the law of contradiction ${ }^{14}$ ). But this resulting conditional is nothing other than the (C)-form of Barbara with " $\mathrm{B}$ " as the middle term. Now consider Bocardo(III):

$\mathrm{CoB}$.

CaA.

Therefore, $\mathrm{A} o \mathrm{~B}$.

In (C):

$$
\mathrm{CoB} \rightarrow(\mathrm{CaA} \rightarrow \mathrm{AoB})
$$

which is equivalent by (IP) to

$$
\mathrm{C} a \mathrm{~A} \rightarrow(\mathrm{CoB} \rightarrow \mathrm{AoB})
$$

And this, by contraposition, to

$$
\mathrm{C} a \mathrm{~A} \rightarrow(\mathrm{A} a \mathrm{~B} \rightarrow \mathrm{C} a \mathrm{~B})
$$

By another application of (IP) is obtained:

$$
\mathrm{A} a \mathrm{~B} \rightarrow(\mathrm{C} a \mathrm{~A} \rightarrow \mathrm{C} a \mathrm{~B})
$$

which is again Barbara in $(\mathrm{C})$, with " $\mathrm{A}$ " as the middle term.

Conversio syllogismi then takes the following form. From the (C)-form of a first figure mood, one obtains the (C)-form of a second figure mood just by contraposing the main consequent. And to obtain a third-figure from a first-figure (C)-form, one needs to apply (IP) first, then contrapose the main consequent, and finally apply (IP) again.

Consider Barbara in (C):

$$
\mathrm{B} a \mathrm{C} \rightarrow(\mathrm{A} a \mathrm{~B} \rightarrow \mathrm{A} a \mathrm{C})
$$

Contraposing the main consequent, one obtains:

$$
\mathrm{B} a \mathrm{C} \rightarrow(\mathrm{Aoc} \rightarrow \mathrm{AoB})
$$

which is Baroco(II) in (C) with "C" as the middle term. Now consider again Barbara in (C) - apply first, this time, (IP):

$$
\mathrm{A} a \mathrm{~B} \rightarrow(\mathrm{B} a \mathrm{C} \rightarrow \mathrm{A} a \mathrm{C})
$$

\footnotetext{
${ }^{14}$ The paranthetical addition is not unimportant, as will be seen in the following.
} 
Contrapose the main consequent, and apply (IP) again:

$$
\mathrm{A} o \mathrm{C} \rightarrow(\mathrm{A} a \mathrm{~B} \rightarrow \mathrm{B} o \mathrm{C})
$$

What is obtained is Bocardo(III) in (C) with " $\mathrm{A}$ " as the middle term. Thus, every valid mood of the second figure deducible in this way is actually of the general form

$$
\text { Major. }
$$

Not Conclusion.

Therefore, not Minor.

and every valid mood of the third deducible in the same way, of

Not Conclusion.

Minor.

Therefore, not Major.

where the premisses are in the usual order, and "Major", "Minor" and "Conclusion" represent the major premiss, minor premiss and the conclusion of the original first-figure mood, respectively.

Barbara gives, by means of this method, its very siblings in the standard reduction scheme, but this is not the case for the remaining perfect moods. Consider, for instance, Celarent in $(\mathrm{C})$ :

$$
\mathrm{BeC} \rightarrow(\mathrm{A} a \mathrm{~B} \rightarrow \mathrm{AeC})
$$

Contraposing the main consequent gives the (C)-form, not of Cesare or Camestres but of Festino(II):

$$
\mathrm{BeC} \rightarrow(\mathrm{AiC} \rightarrow \mathrm{AoB})
$$

So with this simple procedure, the following six groups of syllogistic moods result:

1. Barbara(I): Baroco(II) and Bocardo(III)

2. Celarent(I): Festino(II) and Disamis(III)

3. Darii(I): Camestres(II) and Ferison(III)

4. Ferio(I): Cesare(II) and Datisi(III)

5. Barbari(I): Camestrop(II) and Felapton(III) 


\section{Celaront(I): Cesaro(II) and Darapti(III). ${ }^{15}$}

Each of these groups constitutes a genuine triple, for the only two other moods one could obtain from any imperfect mood from any one of these groups, only by applying contraposition and (IP), are the very two other members of the same group.

It is notable that Darapti(III) and Felapton(III), traditionally not counted among the subaltern moods, are nevertheless grouped with them. There is actually a sense in which these two as well should be subaltern moods. Observe that, other things remaining the same in a valid syllogistic mood, stronger premisses would a fortiori yield the same conclusion. Therefore, there are in principle two different ways to weaken a syllogistic mood by means of subalternation: subalternating its conclusion (as in the case of the traditional subalterns) or superalternating one of its premisses. So Darapti and Felapton can be considered in this widened sense subaltern moods of the third figure, for Darapti can be obtained from Datisi(III) or Disamis(III) by superalternating the minor or the major premiss (respectively), and Felapton from Ferison(III) by superalternating the minor.

\subsection{The scheme and syllogistic expansions}

We can describe Leibniz's alternative reduction scheme, $L R$, in five steps:

i. By means of syllogistic expansion, subalternation is proved to be valid in the first figure (via Darii and Ferio).

ii. By means of subalternation, the two subaltern moods of the first figure are obtained. Hence there are six valid moods in the first figure.

iii. By means of conversio syllogismi, all the 12 valid moods of the direct subsidiary ${ }^{16}$ figures, i.e. the second and third figures (six per each), are obtained from the six valid first-figure moods.

iv. By means of syllogistic expansion, simple and per accidens conversions are proved to be valid in the direct subsidiary figures.

$\mathrm{v}$. By means of simple and per accidens conversions, the fourth-figure valid moods are reduced to the first figure.

LR thus effectively employs only three principles of immediate inference: simple and per accidens conversions for the reduction of the fourth-figure (main) moods, and subalternation for deducing the first-figure (and fourth-figure) subaltern moods. Conversions can be proved by expanding them to two-termed second- and third-figure

\footnotetext{
${ }^{15}$ Cf. Couturat (1901) ch. 1, section 9 (p. 15 seqq.), where a distinction between universal and particular moods is at the center.

${ }^{16}$ Leibniz calls in the Nouveaux Essais (p. 364) all the non-first figures "subsidiary", but among them, only the second and third figures "direct". So the fourth figure is an indirect subsidiary figure. This terminology might be echoing the medieval denial of a fourth figure: see footnote 8 above.
} 
valid syllogisms (step (iv)), and the two subalternations can be proved by expanding them to two-termed first-figure valid syllogisms (step (i)). ${ }^{17}$

I list the expansions one by one. $e$ simple conversion is expanded to a two-termed syllogism in Cesare(II) with "B" as the middle and minor term:

$\mathrm{AeB}$.

$\mathrm{B} a \mathrm{~B}$.

Therefore, $\mathrm{B} e \mathrm{~A}$.

$i$ simple conversion to a two-termed Datisi(III) with " $\mathrm{A}$ " as the middle and major:

$\mathrm{A} a \mathrm{~A}$.

AiB.

Therefore, BiA.

Conversion per accidens of $a$ to a two-termed Darapti(III) with " $\mathrm{A}$ " as the middle and major:

$\mathrm{A} a \mathrm{~A}$.

$\mathrm{A} a \mathrm{~B}$.

Therefore, BiA.

$a-i$ subalternation to a two-termed Darii with " $\mathrm{A}$ " as the middle and minor:

$\mathrm{A} a \mathrm{~B}$.

AiA.

Therefore, AiB.

And finally, e-o subalternation to a two-termed Ferio with " $\mathrm{A}$ " as the middle and minor:

$\mathrm{AeB}$.

AiA.

Therefore, AoB.

17 The idea of expanding conversion inferences to syllogisms is present in the Animadversiones Aristotelicae of the Renaissance logician Petrus Ramus (also mentioned in the Nouveaux Essais). See Lachelier (1907) pp. 56, fn. 1 . 
The account of the reduction of the fourth figure is absent from De Formis Syllogismorum, but following the number 24 and the manner of reduction mentioned in the Nouveaux Essais, it appears that the fourth figure should consist of the standard list: Bramantip (Bamalip), Camenes (Calemes), Dimaris (Dimatis), Fesapo and Fresison, and the subaltern Camenop. ${ }^{18}$ As the letter " $\mathrm{m}$ " (for mutari, i.e. to be changed) indicates, the first three are standardly perfected by means of premiss interchange and conversion (simple or per accidens), and Camenop from Camenes. Fesapo and Fresison are standardly reduced to Ferio without recourse to premiss interchange. But following the observation about Darapti(III) and Felapton(III) above, Bramantip and Fesapo can alternatively be considered subalterns of Dimaris and Fresison, respectively. The list of all Leibnizian valid moods, with 15 main moods and 9 subalterns, will then run:

I: Barbara, Celarent, Darii, Ferio - Barbari, Celaront.

II: Baroco, Festino, Camestres, Cesare-Cesaro, Camestrop.

III: Bocardo, Disamis, Ferison, Datisi - Felapton, Darapti.

IV: Camenes, Dimaris, Fresison-Camenop, Bramantip, Fesapo.

\section{Observations}

I make two evaluative observations in this section, one concerning the method of conversio syllogismi, the other the syllogistic expansion of subalternation, respectively. They jointly point to the fact that the key to the wellness of a syllogistic reduction scheme - and especially of LR - is its interpretation of the basic propositional forms.

Both observations critically revolve around the Leibnizian notion of primary truth, so it will be better first to take a glance at this notion. Leibniz famously classifies truths in $\mathrm{La}$ Monadologie $\$ 33$ into those of reason/reasoning (de Raisonnement) and those of fact (de Fait), according to a modal principle: the former are necessarily and the latter only contingently so. He then explains the notion of necessary truth in $\$ \S 34-35$ by recourse to notions of mathematical axiomatization: a necessary truth is one that can be proved (in finite steps of reasoning) using only simplest ideas, which function like definitions in an axiomatic system, and simplest truths, which function like axioms and postulates of the system. One should consider these simplest truths as primitive principles (principes primitifs), "which could not, nor would need to, be proved; and these are identical statements (énonciations identiques) whose opposite contains a definite contradiction". ${ }^{19}$

\footnotetext{
${ }^{18}$ In the face of variations in the pronunciation of the traditional names of syllogistic moods, I have somewhat arbitrarily chosen to follow the pronunciations that appear in Detlefsen et al. (1999). Note that adherents of the orthodox (i.e., Aristotelian-medieval) conception of the fourth figure moods as indirect moods of the first figure have felt need to use alternative codifications for these moods, such as "Celantes" instead of "Camenes", or "Dabitis" instead of "Dimaris". See on this point Lachelier (1907) p. 30.

${ }^{19}$ Leibniz (1875-90/1965) p. 612 (my translation).
} 
Primary truths of reason are thus identical statements, or simply identities, i.e. selfevidently valid formulae which merely express instances of repetitive cognition, ${ }^{20}$ so which do not bring any real burden of assumption to the reasonings in which they are employed - they are automatically and implicitly employed, as it were, in every possible reasoning.

\subsection{Contradictory opposition and conversio syllogismi}

The first observation concerns Leibniz's deflation of the method of conversio syllogismi. Now the whole point of introducing LR is to provide inferential parsimony. LR proves the immediate inferences it employs by means of valid syllogisms, so the only assumptions it makes are the validity of the perfect moods and the method of conversio syllogismi. However, even this method, for Leibniz, does not constitute a genuine assumption, for it stands solely on a "primary truth of reason", namely, the principle of contradiction, which he formulates in the Nouveaux Essais in the following way:

Stated generally, the principle of contradiction is: a proposition is either true or false. This contains two assertions: first, that truth and falsity are incompatible in a single proposition, i.e. that a proposition cannot be both true and false at once; and second, that the contradictories or the negations of the true and the false are not compatible, i.e. that there is nothing intermediate between the true and the false, or better that it cannot happen that a proposition is neither true nor false. (Leibniz, 1996, p. 362) (original pagination)

A modern mind might be at unease with this formulation, given the distinction between a (weaker) principle of contradiction, which is actually in conformity with polyvalent logics, and a tertium non datur, which guarantees bivalence. ${ }^{21}$ But what is really important here is the semantic status of (what Leibniz sees as) the principle of contradiction: it is a (negative) primary truth of reason, and it is this special status that deflates conversio syllogismi (and accordingly LR as a whole).

However, here is disregarded the contribution of an oppositive immediate inference, distinct from the principle of contradiction: the oppositive law of contradiction saying that $a-o$ opposition and $e-i$ opposition are contradictions. A principle of contradiction is merely intended to tell us what it is for a couple of propositions to be contradictories; the law of contradiction, on the other hand, tells us which pairs of categorical propositions are contradictories. So one should employ both the principle and the law of contradiction

\footnotetext{
${ }^{20}$ Leibniz (1996) p. 361. Note that, for Leibniz, who considers praedicatum inesse subjecto as a univocal definition of truth (Kneale \& Kneale, 1962, p. 323), every truth in the last instance is in some sense repetitive (analytic). Truths of reason are explicitly so, for a finite analysis of the subject concept which shows that the predicate is contained in it is available, whereas truths of fact, i.e. truths concerning particular members of the contingently existing universe, are only virtually analytic, because an infinite mind is required to complete their analytic proof. These issues concern Leibniz's semantics/metaphysics of alethic modalities, particularly his doctrine of notio completa, to which I cannot give any place here.

${ }^{21}$ Belna (2014) p. 12. Jean-Pierre Belna reminds us that the principle of contradiction, unlike the tertium non datur, appears in Aristotle in a rather metaphysical clothing.
} 
in order to make conversio syllogismi work. ${ }^{22}$ But this oppositive law is not a primary truth of reason by Leibniz's standards, for it does not seem to be self-evidently true: it is not evident by itself, for example, that a universal affirmative is in contradiction with the opposed particular negative, instead of, say, the opposed universal negative, unless a natural interpretation of these forms says so. And a natural interpretation of that sort does not seem to be available (more on this below).

Note that on this point, LR is on a par with the standard scheme: the latter needs as well to verify the oppositive law, for it is bound to employ the indirect method to reduce Baroco(II) and Bocardo(III). But there is another, more important condition that LR has to meet, shown in the following subsection.

\subsection{Syllogistic expansion or syllogism proper?}

The second observation concerns that which really provides the intended parsimony of LR, namely, syllogistic expansions of immediate inferences. Leibniz plainly trades in these expansions on the intuition that identical categoricals of the form "All A is A" and "Some A is A" are likewise primary truths. The justificatory effect of this intuition can be put in a logical shape via the equivalences

(SE1) $\mathrm{p} \rightarrow(\mathrm{T} \rightarrow \mathrm{q}) \equiv \mathrm{p} \rightarrow \mathrm{q}$

(SE2) $\mathrm{T} \rightarrow(\mathrm{p} \rightarrow \mathrm{q}) \equiv \mathrm{p} \rightarrow \mathrm{q}$

where " $\mathrm{T}$ " represents the relevant identical categorical, and " $\mathrm{p} \rightarrow \mathrm{q}$ " is a valid formula if and only if the relevant original sub-syllogistic inference from " $\mathrm{p}$ " to " $\mathrm{q}$ " is valid. (SE1) applies to expansions whose minor premiss, and (SE2) to those whose major premiss, is an identical categorical. (Of course (SE1) $\equiv(\mathrm{SE} 2)$ by $(\mathrm{IP})$.)

Now Leibniz's intention is to show, not that immediate inferences are not really immediate ${ }^{23}$ (i.e. single-premissed), but instead that they can be verified by means of valid syllogistic moods; but if the identical categoricals that "enter" into the reasoning in their syllogistic expansions are not primary truths, then the reasoning would be mediate, as the matter of being valid would depend on the relation between the truth of the conclusion and the truth of two distinct premisses. Just because there is no real matter of these identical categoricals' being true, the reasoning does not cease to be immediate. This is why it is better to call them expansions instead of syllogisms proper (of this or that sort).

However, the self-evidentiality of the (affirmative) identical categoricals is just doubtful. Modern quantificational canonical renderings of the traditional categoricals easily

\footnotetext{
22 Actually, the first Stoic thema, too (Kneale \& Kneale, 1962, p. 323).

23 This is exactly Jules Lachelier's view of immediate inferences, which he famously defends in his essay

“Les Conséquences Immédiates et le Syllogisme" (1876), contained in Lachelier (1907).
} 
ground this doubt. While the universal identical form is standardly rendered as a universally quantified iterative conditional of the form

$$
\forall \mathrm{x}(\mathrm{Ax} \rightarrow \mathrm{Ax})
$$

which comes out as valid, the particular identical form takes the existentially quantified iterative conjunctive form

$$
\exists x(A x \& A x)
$$

reducing to

$$
\exists x(\mathrm{Ax})^{24}
$$

which is simply not a valid formula. The standard colloquial reading of this reduced form is one of "As exist", "There are As" or "There is an A". This is noteworthy, as it illustrates exactly the way subalternation is invalidated in modern logic: the universal categorical entails the (opposed) particular only under the assumption that the subject term is non-empty (Klima, 2009, p. 144), and indeed the form " $\exists x(\mathrm{Ax})$ " expresses this very assumption. Thus, from the perspective of modern logic, the Leibnizian expansions

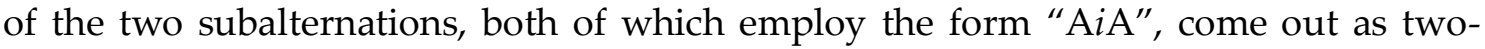
premissed mediate inferences that illustrate the incapability of the relevant universal to entail the particular.

At this juncture, one can follow (at least) three different strategies: one can (i) reject the standard canon of translation in which particular affirmatives come out as existentially quantified conjunctions and hold that subalternation is valid; or (ii) accept the standard canon and conclude that subalternation is invalid; or (iii) accept the standard canon, but relativize the matter of the validity of subalternation to the question whether the specified universe of discourse is actualia or possibilia. An instance of an attempt to follow route (i) is Jacquette (2015), ${ }^{25}$ which (consciously) fails in preserving the other laws of opposition; and route (ii), which is briefly stated in the preceding paragraph, is indeed the standard view. Route (iii), on the other hand, can be taken to be the one followed by Leibniz himself in some of his writings: the existential form " $\exists x(\mathrm{Ax})$ " is to state merely the possibility of A, in other words, that at least one possible entity is A. This strategy will reappear below.

\footnotetext{
${ }^{24}$ On this point, see also Wolfgang Lenzen's entry (indexically dated 2018) on Leibniz's logic in The Internet Encyclopedia of Philosophy.

25 The critical move in Dale Jacquette's strategy is to translate the particular affirmative form as an existential quantification with a conditional instead of a conjunctive matrix.
} 


\subsection{Determining the criteria for possible interpretations}

Let me illustrate how these two observations turn into two criteria for a proper interpretation LR has to give for the categorical forms. Leibniz admits elsewhere ${ }^{26}$ that syllogistic reductions do make use of oppositive laws. There he holds interestingly that these laws are primitive (i.e. primary truths) as they stem from the same source with the perfect moods, namely, the dictum de omni et nullo, but the explanation he gives - in terms of a reading of universal categoricals as infinite conjunctions and particulars as infinite disjunctions - is far from satisfactory. But a little later on he briefly presents his "old analysis", which is an "interpretation" 27 of the categorical forms that is intended to verify the oppositive laws.

Under this interpretation, categoricals come out as affirmations or denials of the entityhood (which can be taken to mean possible instantiation) of complex concepts. For instance, the $a$ form "All A is B" is rendered "A non-B is non-entity" while the opposed $o$ is rendered "A non-B is entity"; again, the related $e$ and $i$ forms are interpreted, respectively, as " $\mathrm{AB}$ is non-entity" and " $\mathrm{AB}$ is entity". These renderings clearly - at least more clearly - verify the law of contradiction, for they make it that what a universal affirmative/negative denies will be simply affirmed by the corresponding particular negative/affirmative. Leibniz says (Leibniz, 1966, p. 116): “From this interpretation there are evident at once the rules of opposition (by which I have proved the second and third figures from the first) and the laws of conversion (by which I have proved the fourth figure) as is clear from the terms themselves." Even simple conversions of $e$ and $i$ forms can indeed be taken to be verified by this interpretation, as the conceptual complexity of which they deny or affirm entity-hood should not alter with a change in the order of the constituents.

The case of subalternation is rather informative. Under this interpretation, universal categoricals, whether affirmative or negative in the colloquial reading, all become propositions of denial, and accordingly, the particulars become propositions of positing (thesis). From a denial should not follow any positing, so, contrary to what Leibniz says, the two subalternations simply do not hold.

But we should also consider the interpretation of identical categoricals, for if the " $\mathrm{A} i \mathrm{~A}$ " form under this interpretation come out as a valid formula, then subalternation can

\footnotetext{
${ }^{26}$ In a logical paper written after 1690 (Difficultates quaedam logicae): Parkinson (1966) pp. 115-121. The same paper has been the main source for the common ascription to Leibniz of a model-theoretical solution to the question of subalternation (or of non-emptiness at large).

${ }^{27}$ I use this term with great caution, for it is highly debatable that the translations Leibniz gives for the categoricals in his "old analysis" are elements of an interpretation in the modern mathematical sense. Nicholas Rescher shows, contra Couturat (1901), that Leibniz is perfectly conscious of the distinction between an abstract logical calculus and its possible different interpretations, but the "interpretation" given here is not among the instances Rescher considers as exemplifications of that consciousness. See Rescher (1954) for Leibniz's extensional, intensional and strict implicational interpretations (in the modern sense) of his own logical calculi (cf. Kneale \& Kneale, 1962, p. 339).
} 
flawlessly be proved by syllogistic expansion in the first figure, and with simple conversion at hand, conversion per accidens will just follow. (Moreover, the remaining traditional laws of opposition, i.e. contrariety and sub-contrariety, will be easily obtained, given subalternation and the law of contradiction.) Identical forms under this interpretation will be:

A $a$ A: A non-A is non-entity.

AiA: AA (=A) is entity.

Now suppose " $\mathrm{A}$ " itself has the form "B non-B", i.e. $\mathrm{A}$ is a non-entity. "A $a \mathrm{~A}$ " will then have the explicit form

$$
\text { (B non-B) non-(B non-B) is non-entity. }
$$

This is trivially true, since "B non- $\mathrm{B}$ " is itself a non-entity. So when A is a non-entity, every universal predication with " $\mathrm{A}$ " as the subject is true irrespective of the content of the predicate; but "A $\mathrm{A}$ ",

\section{B non-B is entity}

will (for every value of " $\mathrm{B}$ ") be false. This shows that in order for subalternation to be proved by syllogistic expansion under this interpretation, an entity-hood assumption for the subject term is required. But this assumption is nothing other than a non-emptiness assumption only for a much larger extension, i.e. the set of possible As. So, the nature of the failure of the syllogistic expansion of subalternation remains unchanged under this interpretation.

Other kinds of interpretation can possibly be proposed, which entail the identical forms without recourse to a non-emptiness assumption of the above sort. The bottom line is that a proper interpretation for LR has to verify at the least, aside from the oppositive law of contradiction, the identical categorical forms employed in syllogistic expansions. Syllogistic expansion as a deductive trick does not come without its (semantic) burdens.

\section{Conclusion}

Syllogism is definitely an infertile form of reasoning in terms of deductive feasibility, although Aristotle equated it with the idea of proof in general. Leibniz's procedure for syllogistic reductions through two-termed syllogisms is one instance of pushing this form beyond its natural limits. The procedure does not seem to culminate in an outright failure, but its state confirms the thesis that there is no syllogistic that should not rely on any one of the traditional immediate inferences but should account for all of them.

The locking element is the semantical opacity of the traditional categorical forms of proposition, which lock can be removed only by a proper interpretation of these forms. But once a proper interpretation is obtained, one or more immediate inferences will most probably follow, disabling the indispensability of the syllogistic form for deduction at 
large. Indeed, the syllogistic form was originally intended to capture syllogisms, not subsyllogistic inferences.

\section{REFERENCES}

Aristotle (1963). Aristotle: Categories and De Interpretatione (J. L. Ackrill, Trans. \& Notes). Oxford: Oxford University Press.

Aristotle (2009). Prior Analytics: Book I (G. Striker, Intr. \& Com.). Oxford: Oxford University Press.

Belna, J.-P. (2014). Histoire de la Logique. Paris: Ellipses.

Chenique, F. (2006). Éléments de la Logique Classique. Paris: L'Harmattan.

Couturat, L. (1901). La Logique de Leibniz (d'après des documents inédits). Paris: Presses Universitaire de France.

Detlefsen, M. \& McCarty, D. C \& Bacon, J. B. (1999). Logic from A to Z. London: Routledge. Klima, G. (2009). John Buridan. Oxford: Oxford University Press.

Kneale, W. \& Kneale, M. (1962). The Development of Logic. Oxford: Clarendon Press.

Jacquette, D. (2016). Subalternation and Existence Presuppositions in an Unconventionally Formalized Canonical Square of Opposition. Logica Universalis, 10(23), 191-213.

Lachelier, J. (1907). Études sur le Syllogisme (suivies de l'observation de Platner et d'une note sur le "Philèbe"). Paris: Librairie Félix Alcan.

Leibniz, G. W. (1875-90). Die Philosophischen Schriften 6 (7 vols.) (C. I. Gerhardt, Ed.). Berlin: Weidmann. (Reprinted 1965, Hildesheim: Georg Olms).

Leibniz, G. W. (1966). Logical Papers (G. H. R. Parkinson, Trans. \& Ed.). Oxford: Oxford University Press.

Leibniz, G. W. (1996). New Essays on Human Understanding (P. Remnant \& J. Bennett, Trans. \& Ed.). Cambridge: Cambridge University Press.

Lenzen, W. (n.d.). Leibniz: Logic. In The Internet Encyclopedia of Philosophy. Retrieved from http://www.iep.utm.edu/leib-log

Miller, J. W. (1938). The Structure of Aristotelian Syllogistic. London: K. Paul, Trench, Trubner \& Co. 
Parsons, T. (2014). Articulating Medieval Logic. Oxford: Oxford University Press.

Patzig, G. (1968). Aristotle's Theory of the Syllogism (J. Barnes, Trans.). Dordrecht: Springer.

Rescher, N. (1954). Leibniz's Interpretation of His Logical Calculi. The Journal of Symbolic Logic 19(1), 1-13. 